\title{
Pre-pregnancy overweight and weight gain during pregnancy increase the risk of gestational anemia
}

\author{
Dirk L Christensen \\ Kobenhavns Universitet \\ Maritsa Solano \\ Instituto Nacional de Salud Publica \\ Héctor Lamadrid-Figueroa \\ Instituto Nacional de Salud Publica \\ Laura Avila \\ Instituto Mexicano del Seguro Social \\ Rebeca Trejo-Reyes \\ Instituto Nacional de Salud Publica \\ Omar Domínguez-Flores \\ Instituto Nacional de Salud Publica \\ Ivonne Ramírez-Silva \\ Instituto Nacional de Salud Publica \\ Juan A Rivera \\ Instituto Nacional de Salud Publica
}

Alejandra Cantoral ( $\square$ alejandra.cantoral@insp.mx )

Instituto Nacional de Salud Publica https://orcid.org/0000-0002-1397-8476

\section{Research note}

Keywords: pregnancy, anemia, overweight

Posted Date: January 8th, 2020

DOI: https://doi.org/10.21203/rs.2.20373/v1

License: (c) (1) This work is licensed under a Creative Commons Attribution 4.0 International License.

Read Full License 


\section{Pre-pregnancy overweight and weight gain during pregnancy increase the risk of gestational anemia}

Cantoral Alejandra*, Center for Nutrition and Health Research, National Institute of Public Health, Av. Universidad 655, Col Sta Ma Ahucatitlán, 62230, Cuernavaca, Morelos, México. Phone +52 (777) 3293000 alejandra.cantoral@insp.mx

Christensen Dirk L., Department of Public Health, Section of Global Health, University of Copenhagen. Oster Farimagsgade 5, CSS building 9, 1014, Copenhagen K, Denmark. dirklc@sund.ku.dk

Solano Maritsa, Center for Nutrition and Health Research, National Institute of Public Health, Av. Universidad 655, Col Sta Ma Ahucatitlán, 62230, Cuernavaca, Morelos, México.msolano@insp.mx

Lamadrid-Figueroa Héctor ${ }^{1}$, Center for Public Health Research, National Institute of Public Health, Av. Universidad 655, Col Sta Ma Ahucatitlán, 62230, Cuernavaca, Morelos, México.hlamadrid@insp.mx

Ávila Laura, Morelos Delegation, Mexican Institute of Social Security. Blvd. Benito Juarez 18, Col Centro, 62100, Cuernavaca, Morelos, México. laura.avila@imss.gob.mx

Trejo-Reyes Rebeca, Center for Nutrition and Health Research, National Institute of Public Health, Av. Universidad 655, Col Sta Ma Ahucatitlán, 62230, Cuernavaca, Morelos, México. rbk_7580@ hotmail.com

Omar Domínguez-Flores, Center for Nutrition and Health Research, National Institute of Public Health, Av. Universidad 655, Col Sta Ma Ahucatitlán, 62230, Cuernavaca, Morelos, México.omi_d95@hotmail.es 
Ramírez-Silva Ivonne, Center for Nutrition and Health Research, National Institute of Public Health, Av. Universidad 655, Col Sta Ma Ahucatitlán, 62230, Cuernavaca, Morelos, México. ciramir@insp.mx

Rivera Juan A. General Director, National Institute of Public Health, Av. Universidad 655, Col Sta Ma Ahucatitlán, 62230, Cuernavaca, Morelos, México. jrivera@insp.mx

*Corresponding Author

\begin{abstract}
Objective: To study the double burden of overweight and anemia in Mexican women during pregnancy and if pre-pregnancy body mass index (BMI) and weight gain are associated with the development of anemia. In a sample of 98 pregnant women from an ongoing birth cohort, weight and hemoglobin at different gestational weeks, as well as prepregnancy BMI (self-reported) were obtained. An adjusted logistic model for longitudinal data was used to estimate the probability of presenting anemia according to pre-pregnancy overweight status $\left(\mathrm{BMI} \geq 25 \mathrm{~kg} / \mathrm{m}^{2}\right)$ and weight gain, including an interaction term between these two variables.
\end{abstract}

Results: At the end of pregnancy the combined prevalence of overweight and anemia was $18 \%$. The probability of developing anemia was different from zero among overweight women at the beginning of pregnancy and weight gain $\geq 6.5 \mathrm{~kg} \mathrm{~kg}$ (up to $8 \%, \mathrm{p}<0.05$ ); furthermore, the prevalence was higher than zero in those women with a normal prepregnancy BMI $\left(<25 \mathrm{~kg} / \mathrm{m}^{2}\right)$ and a weight gain $\leq 12 \mathrm{Kg}$ (up to $9 \%, \mathrm{p}<0.05$ ). In conclusion anemia increases with the combinations of low weight gain in women with a normal prepregnancy BMI as well as excessive weight gain in women with pre-pregnancy overweight.

Key words: pregnancy, anemia, overweight 


\section{Introduction}

In Mexico, the prevalence of overweight and obesity in women of reproductive age (20-49 years) has increased dramatically (42.4\%) over the last three decades [1]. Nowadays, more than $70 \%$ of women of reproductive age have a body mass index (BMI) above $25 \mathrm{~kg} / \mathrm{m}^{2}$ [2]; furthermore, around $30 \%$ of women are expected to have a BMI $\geq 30 \mathrm{~kg} / \mathrm{m}^{2}$ when they become pregnant [3]. At the same time, anemia has declined since the 1990s but the current

prevalence of anemia in women of reproductive age is still high at $22 \%$ [4]. Furthermore, overweight and anemia during pregnancy are associated with adverse health outcomes in mother and offspring [5-7].

It has been recognized that overweight may contribute to low iron status, as BMI is negatively correlated to serum iron [8], and iron deficiency is more common in overweight than normal-weight children and women [9-12]. This correlation has been documented in Mexico since 1999, when the National Nutrition Survey showed that the risk of iron deficiency in obese children and women of reproductive age was 2-4 times that of individuals with a healthy weight at similar dietary iron intakes [10].

In the case of pregnant women, some studies have shown that a high BMI previous to and during pregnancy influence iron stores negatively [13-15]; pre-pregnant obese women have lower ferritin concentrations than pre-pregnant non-obese women [13].

Other studies have examined the association between obesity and iron status in pregnant woman and their offspring [16-18]. Although deficiencies, like anemia, and conditions of excess, such as overweight, might seem opposite to one another, they share environmental conditions and behaviors and can co-occur at the household and individual level; this cooccurrence has been named the "double burden of malnutrition" [19-21]. A previous study documented that Mexican women of reproductive age from mildly and moderately food insecure households, were more likely to experience concurrent anemia and overweight than were women from food secure households [22]. This probably reflects simultaneous overconsumption of high-energy products and nutrient-poor diets [22]. 
The two conditions, iron deficiency-anemia and overweight could be interlinked through: poor dietary quality, diets restricted in total iron or animal-source iron and calorie rich diets; increased iron requirements during pregnancy, or impaired iron absorption related to higher levels of hepcidin resulting from obesity-related inflammation [8, 14, 23-25].

It is highly relevant to study not only the prevalence of overweight plus anemia during pregnancy in a country where both conditions are public health problems, but also to study if the pre-pregnancy BMI and weight gain during pregnancy are associated with the development of anemia.

\section{Main text}

\section{Methods}

The study is based on a subsample of 98 pregnant women from an ongoing birth cohort study (named MAS-Lactancia, in Spanish) that was initiated in 2016, and in which over 954 pregnant women have been recruited. Mothers were considered for inclusion in the study if they were between 18 to 39 years of age, in gestation weeks between 3 to 22, planned to live in the area of Cuernavaca for 3 years after delivery, and with the intention of delivery at the IMSS General Hospital in Cuernavaca. Exclusion criteria included woman with (1) more than one fetus, (2) high-risk pregnancy, (3) history or diagnosis of hypertension, (4) hypertensive diseases of pregnancy, (5) with renal, liver, heart or cardiovascular disease, (6) endocrine disorders, (7) preterm births (<37 weeks gestation), and (8) abuse of drugs.

After reviewing the clinical files of the total sample $(n=954)$, we included 98 pregnant women as they were the ones with complete and available information on hemoglobin and anthropometry through pregnancy. We reviewed the clinical files of participants in the study and recorded the following variables: pre-pregnancy weight (self-reported), age, and parity. During prenatal care visits weight and height were measured (Weight, using light clothing with a Bame scale, with a precision of $100 \mathrm{~g}$. Height, using a Health-o-Meter stadiometer with a precision of $0.1 \mathrm{~cm}$ ) as well as gestational age (weeks) determined by last menstrual 
date or by ultrasonography. Hemoglobin levels were also obtained from the files (analyzed by UniCel DxC 600/800 SYNCHRON) and recorded in the files with the corresponding gestational age.

Pre-pregnancy BMI was estimated as weight $(\mathrm{kg}) /$ height $\left(\mathrm{m}^{2}\right)$, and pre-pregnancy overweight was defined as $\geq 25 \mathrm{~kg} / \mathrm{m}^{2}$. Weight gain was estimated using the pre-pregnancy self-reported weight and the current weight of each visit (by the corresponding gestational age). Anemia was defined according to WHO as adjusted hemoglobin by altitude $<11.0 \mathrm{~g} / \mathrm{dL}$ [26].

Statistical analysis: Descriptive statistics are presented for variables at baseline as mean (SD) and ranges. A random-effects logistic regression model for longitudinal data was fit to estimate the probability of having anemia according to pre-pregnancy overweight status and weight gain, including an interaction term between these two variables. The model was adjusted for age, previous pregnancies and gestational age. All analyses were run in Stata 15.0 (StataCorp LLC)

\section{Results}

Women were followed during pregnancy, with a variation of 1 to 5 prenatal visits in the prenatal care of IMSS clinics (average 2 prenatal visits). Mean age was 28.0 (SD 4.6) years, with $\sim 50 \%$ being overweight at the beginning of pregnancy (Table 1). We compared the analytical sample versus the rest of the cohort, and did not find any differences in the following variables: age, socioeconomic status, education level and parity (data not shown).

Mean hemoglobin was 13.0 (SD 0.0) $\mathrm{mg} / \mathrm{dL}$ during recruitment and none presented with anemia. At the end of pregnancy, the median weight had increased by $9 \mathrm{~kg}$ (IQR $6.5-12.0$ ), $71 \%$ presented with overweight $\left(\mathrm{BMI} \geq 25 \mathrm{~kg} / \mathrm{m}^{2}\right)$, and $18 \%$ had a combination of overweight and anemia $\left(\mathrm{BMI} \geq 25 \mathrm{~kg} / \mathrm{m}^{2}\right.$ and hemoglobin $\left.<11.0 \mathrm{~g} / \mathrm{dL}\right) ; 3 \%$ presented with anemia and normal BMI $\left(\mathrm{BMI}<25 \mathrm{~kg} / \mathrm{m}^{2}\right.$ and hemoglobin $\left.<11.0 \mathrm{~g} / \mathrm{dL}\right)$, and $8 \%$ had normal BMI as well as normal hemoglobin levels at the end of pregnancy. 
Figure 1 presents the predicted probabilities of anemia $(95 \% \mathrm{CI})$ of the adjusted randomeffect model, which show an interaction between pre-pregnancy BMI status and weight gain $(\mathrm{p}<0.07)$. For those women who started the pregnancy with a normal BMI $\left(<25 \mathrm{~kg} / \mathrm{m}^{2}\right)$ and during pregnancy gained, $6.5 \mathrm{~kg}\left(25^{\text {th }}\right.$ percentile), $9 \mathrm{~kg}$ (50th percentile), and $12 \mathrm{~kg}\left(75^{\text {th }}\right.$ percentile) the probability of presenting with anemia was $9 \%, 7 \%$ and $5 \%$ respectively. In contrast, for those women who started the pregnancy with overweight $\left(\mathrm{BMI} \geq 25 \mathrm{~kg} / \mathrm{m}^{2}\right)$ and during pregnancy gained $6.5 \mathrm{~kg}\left(25^{\text {th }}\right.$ percentile $), 9 \mathrm{~kg}$ (50th percentile) or $12 \mathrm{~kg}\left(75^{\text {th }}\right.$ percentile) the probability of presenting with anemia was $6 \%, 7 \%$ and $8 \%$, respectively. These results were adjusted for maternal age, previous pregnancies, and gestational age.

We found that the probability of presenting anemia during pregnancy increases with the combination of pre-pregnancy BMI classification and the gestational weight gain. For those with the combination of having overweight $\left(\mathrm{BMI} \geq 25 \mathrm{Kg} / \mathrm{m}^{2}\right)$ at the beginning of pregnancy and gestational weight gain between 6.5 to $12 \mathrm{~kg}$, this probability increases up to $8 \%$. This result is highly important for health systems, frequently facing more overweight pregnant women.

\section{Discussion}

In this sub-sample of "healthy" pregnant women, almost $50 \%$ of the participants started pregnancy with a $\mathrm{BMI} \geq 25 \mathrm{~kg} / \mathrm{m}^{2}$ (only one participant presented with a $\mathrm{BMI}<18 \mathrm{~kg} / \mathrm{m}^{2}$ when becoming pregnant), and more than $80 \%$ finished the pregnancy with this condition (71\% with overweight and $18 \%$ with overweight and anemia). Only $11 \%$ of the participants ended the pregnancy with a $\mathrm{BMI}<25 \mathrm{~kg} / \mathrm{m}^{2}(8 \%$ with a normal BMI and $3 \%$ with normal BMI and anemia). We observed that for women with a pre-pregnancy BMI $<25 \mathrm{Kg} / \mathrm{m}^{2}$, the probability of presenting anemia is up to $9 \%$ with a gestational weight gain lower or equal to $12 \mathrm{~kg}$.

Epidemiological studies have shown contradictory results regarding the association between overweight/obesity and anemia in pregnancy. Some have documented that overweight women had an increased risk of low iron status and higher levels of hepcidin and maternal 
inflammation $[17,27]$. Others have shown no relation of obesity during pregnancy and iron status [28]. Furthermore, a study of two cohorts showed that higher BMI in early pregnancy was positively associated with hemoglobin and reduced risk of anemia [29].

The prevalence of the double burden of overweight and anemia during pregnancy in the current study was $18 \%$, which is a higher prevalence rate than other countries with low prevalence of overweight, like Vietnam, in which it was reported that only $2 \%$ of pregnant women presented with both conditions [30]. Our results reflect a country with a nutrition transition that is facing the double burden of malnutrition (excess and deficiency), i.e. overweight and anemia in the same individual. This could be viewed in the context of the data reported by the National Health and Nutrition Survey (2012) showing a prevalence of overweight in women (of reproductive age) above $70 \%$ and a prevalence of iron deficiency of $29 \%$ [31]. Furthermore, the survey reported a combined prevalence of overweight and anemia in women of reproductive age of $10 \%$ [22], and suggest that diet was higher in energy dense foods and inadequate in iron intake due to low availability [32]. Besides diet, iron absorption could be reduced due to higher levels of hepcidin as a result of chronic inflammation [25]. Finally, the normal hemodilution of pregnancy contributes to a decrease in hemoglobin levels; however, we tried to control for this condition by using gestational age as a covariate in the models.

Finally, our data support that pregnant women should follow the US Institute of Medicine (IOM) guidelines for healthy weight gain during pregnancy. These guidelines consider preconception BMI and suggest a range of recommended weight gain by trimester of pregnancy [33], since numerous studies have supported the suitability of these guidelines for positive pregnancy outcomes [34].

\section{Limitations}

- A limitation of the study was that, we consider anemia as being due to iron deficiency instead of measuring ferritin or iron stores, but it has been documented that $>50 \%$ of anemia in pregnancy is due to iron deficiency [35]. 
- In spite of the small sample size, we estimated a statistically significant interaction, which means that with a bigger sample our findings would probably be stronger.

- The main strengths of the study is the longitudinal design with repeated measures of BMI and hemoglobin, which allowed us to capture the effect modification of prepregnancy overweight with the variation of gestational weight gain on the hemoglobin levels.

\begin{abstract}
Abbreviations
BMI: Body Mass Index; IMSS: Instituto Mexican del Seguro Social; WHO: World Health Organization; SD: Standard Deviation

\section{Ethics approval and consent to participate}

Written informed consent was obtained from all the pregnant women include in this analysis as part of the consent of the main cohort. A copy of the written consent is available for review by the Editor-in-Chief of this journal. The study has been carried out by the National Institute of Public Health, in collaboration with the Mexican Institute for Social Security in Cuernavaca, Morelos (IMSS), ethical and research commissions approved the protocol of the cohort.
\end{abstract}

\title{
Consent to publish
}

Not applicable

\section{Availability of data and materials}

The datasets used and/or analysed during the current study are available from the corresponding author on reasonable request.

\section{Competing interests}

The authors declare that they have no competing interests.

\section{Funding}

National Council of Science and Technology (CONACYT grant \# 233439) 


\section{Authors' contributions}

AC, MS, RT-R, OD-F: Collected the patient's data. LA, IR-S coordinated and supervised the fieldwork. AC, DLC, HL-F drafted the manuscript. AC, HL-F made the statistical analysis. JAR, IR-S, DLC revised this manuscript critically. All authors read and approved the final manuscript.

\section{Acknowledgements}

We thank the Instituto Mexicano del Seguro Social (Cuernavaca, Morelos) for their support with this research. 


\section{References}

1. Pública INdS: Informe final de Resultados. In: Encuesta Nacional de Salud y Nutrición de Medio Camino México: 70.

2. Barquera SC, I.; Hernpandez, L.; Pedroza-Tobias, A.: Estado Nutricio en Adultos. In: Encuesta Nacional de Salud y Nutrición, medio camino 2016

2016.

3. Hinkle SN, Sharma AJ, Kim SY, Park S, Dalenius K, Brindley PL, Grummer-Strawn LM: Prepregnancy obesity trends among low-income women, United States, 1999-2008. Matern Child Health J 2012, 16(7):1339-1348.

4. Shamah-Levy T, Mejia-Rodriguez F, Mendez Gomez-Humaran I, De la Cruz-Gongora V, Mundo-Rosas V, Villalpando-Hernandez S: [Trend in the prevalence of anemia in Mexican women of childbearing age from 2006-2016. Ensanut MC 2016]. Salud Publica Mex 2018, 60(3):301-308.

5. Christian P, Stewart CP: Maternal micronutrient deficiency, fetal development, and the risk of chronic disease. J Nutr 2010, 140(3):437-445.

6. Rahmati S, Delpishe A, Azami M, Hafezi Ahmadi MR, Sayehmiri K: Maternal Anemia during pregnancy and infant low birth weight: A systematic review and Meta-analysis. Int J Reprod Biomed (Yazd) 2017, 15(3):125-134.

7. Black RE, Victora CG, Walker SP, Bhutta ZA, Christian P, de Onis M, Ezzati M, GranthamMcGregor S, Katz J, Martorell R et al: Maternal and child undernutrition and overweight in low-income and middle-income countries. Lancet 2013, 382(9890):427-451.

8. Cepeda-Lopez AC, Aeberli I, Zimmermann MB: Does obesity increase risk for iron deficiency? A review of the literature and the potential mechanisms. Int J Vitam Nutr Res 2010, 80(4-5):263-270.

9. Brotanek JM, Gosz J, Weitzman M, Flores G: Iron deficiency in early childhood in the United States: risk factors and racial/ethnic disparities. Pediatrics 2007, 120(3):568-575.

10. Cepeda-Lopez AC, Osendarp SJ, Melse-Boonstra A, Aeberli I, Gonzalez-Salazar F, Feskens E, Villalpando S, Zimmermann MB: Sharply higher rates of iron deficiency in obese Mexican women and children are predicted by obesity-related inflammation rather than by differences in dietary iron intake. Am J Clin Nutr 2011, 93(5):975-983.

11. Moayeri H, Bidad K, Zadhoush S, Gholami N, Anari S: Increasing prevalence of iron deficiency in overweight and obese children and adolescents (Tehran Adolescent Obesity Study). Eur J Pediatr 2006, 165(11):813-814.

12. Tussing-Humphreys LM, Liang H, Nemeth E, Freels S, Braunschweig CA: Excess adiposity, inflammation, and iron-deficiency in female adolescents. J Am Diet Assoc 2009, 109(2):297-302.

13. Berglund SK, Garcia-Valdes L, Torres-Espinola FJ, Segura MT, Martinez-Zaldivar C, Aguilar MJ, Agil A, Lorente JA, Florido J, Padilla C et al: Maternal, fetal and perinatal alterations associated with obesity, overweight and gestational diabetes: an observational cohort study (PREOBE). BMC Public Health 2016, 16:207.

14. Cepeda-Lopez AC, Melse-Boonstra A, Zimmermann MB, Herter-Aeberli I: In overweight and obese women, dietary iron absorption is reduced and the enhancement of iron absorption by ascorbic acid is one-half that in normal-weight women. Am J Clin Nutr 2015, 102(6):1389-1397. 
15. Koenig MD, Tussing-Humphreys L, Day J, Cadwell B, Nemeth E: Hepcidin and iron homeostasis during pregnancy. Nutrients 2014, 6(8):3062-3083.

16. Garcia-Valdes L, Campoy C, Hayes H, Florido J, Rusanova I, Miranda MT, McArdle HJ: The impact of maternal obesity on iron status, placental transferrin receptor expression and hepcidin expression in human pregnancy. Int J Obes (Lond) 2015, 39(4):571-578.

17. Jones AD, Zhao G, Jiang YP, Zhou M, Xu G, Kaciroti N, Zhang Z, Lozoff B: Maternal obesity during pregnancy is negatively associated with maternal and neonatal iron status. Eur $J$ Clin Nutr 2016, 70(8):918-924.

18. Phillips AK, Roy SC, Lundberg R, Guilbert TW, Auger AP, Blohowiak SE, Coe CL, Kling PJ: Neonatal iron status is impaired by maternal obesity and excessive weight gain during pregnancy. J Perinatol 2014, 34(7):513-518.

19. Uauy $\mathrm{R}$, Monteiro CA: The challenge of improving food and nutrition in Latin America. Food Nutr Bull 2004, 25(2):175-182.

20. Kroker-Lobos MF, Pedroza-Tobias A, Pedraza LS, Rivera JA: The double burden of undernutrition and excess body weight in Mexico. Am J Clin Nutr 2014, 100(6):1652S1658 S.

21. Doak CM, Adair LS, Monteiro C, Popkin BM: Overweight and underweight coexist within households in Brazil, China and Russia. J Nutr 2000, 130(12):2965-2971.

22. Jones AD, Mundo-Rosas V, Cantoral A, Levy TS: Household food insecurity in Mexico is associated with the co-occurrence of overweight and anemia among women of reproductive age, but not female adolescents. Matern Child Nutr 2017, 13(4).

23. Cook JD, Dassenko SA, Lynch SR: Assessment of the role of nonheme-iron availability in iron balance. Am J Clin Nutr 1991, 54(4):717-722.

24. Eckhardt CL, Torheim LE, Monterrubio E, Barquera S, Ruel MT: The overlap of overweight and anaemia among women in three countries undergoing the nutrition transition. Eur $J$ Clin Nutr 2008, 62(2):238-246.

25. Zimmermann MB, Zeder C, Muthayya S, Winichagoon P, Chaouki N, Aeberli I, Hurrell RF: Adiposity in women and children from transition countries predicts decreased iron absorption, iron deficiency and a reduced response to iron fortification. Int J Obes (Lond) 2008, 32(7):1098-1104.

26. WHO: Haemoglobin concentrations for the diagnosis of anaemia and assessment of severity. In: Vitamin and Mineral Nutrition Information System. Ginebra: World Health Organization; 2011.

27. Herter-Aeberli I, Thankachan P, Bose B, Kurpad AV: Increased risk of iron deficiency and reduced iron absorption but no difference in zinc, vitamin A or B-vitamin status in obese women in India. Eur J Nutr 2016, 55(8):2411-2421.

28. Cao C, Pressman EK, Cooper EM, Guillet R, Westerman M, O'Brien KO: Prepregnancy Body Mass Index and Gestational Weight Gain Have No Negative Impact on Maternal or Neonatal Iron Status. Reprod Sci 2016, 23(5):613-622.

29. Mocking M, Savitri Al, Uiterwaal C, Amelia D, Antwi E, Baharuddin M, Grobbee DE, Klipstein-Grobusch K, Browne JL: Does body mass index early in pregnancy influence the risk of maternal anaemia? An observational study in Indonesian and Ghanaian women. BMC Public Health 2018, 18(1):873.

30. Laillou A, Yakes E, Le TH, Wieringa FT, Le BM, Moench-Pfanner R, Berger J: Intra-individual double burden of overweight and micronutrient deficiencies among Vietnamese women. PLoS One 2014, 9(10):e110499.

31. Shamah-Levy T, Villalpando S, Mejia-Rodriguez F, Cuevas-Nasu L, Gaona-Pineda EB, Rangel-Baltazar E, Zambrano-Mujica N: Prevalence of iron, folate, and vitamin B12 
deficiencies in $\mathbf{2 0}$ to $\mathbf{4 9}$ years old women: Ensanut 2012. Salud Publica Mex 2015, 57(5):385-393.

32. Sanchez-Pimienta TG, Lopez-Olmedo N, Rodriguez-Ramirez S, Garcia-Guerra A, Rivera JA, Carriquiry AL, Villalpando S: High Prevalence of Inadequate Calcium and Iron Intakes by Mexican Population Groups as Assessed by 24-Hour Recalls. J Nutr 2016, 146(9):1874S1880S.

33. IOM: Weight Gain During Pregnancy: Reexamining the Guidelines. Institute of Medicine (US) and National Research Council (US) and Committee to Reexamine IOM Pregnancy Weight Guidelines. In.: US Institute of Medicine; 2009.

34. Gilmore LA, Redman LM: Weight gain in pregnancy and application of the 2009 IOM guidelines: toward a uniform approach. Obesity (Silver Spring) 2015, 23(3):507-511.

35. Stevens GA, Finucane MM, De-Regil LM, Paciorek CJ, Flaxman SR, Branca F, Pena-Rosas JP, Bhutta ZA, Ezzati M, Nutrition Impact Model Study G: Global, regional, and national trends in haemoglobin concentration and prevalence of total and severe anaemia in children and pregnant and non-pregnant women for 1995-2011: a systematic analysis of population-representative data. Lancet Glob Health 2013, 1(1):e16-25. 
Figures

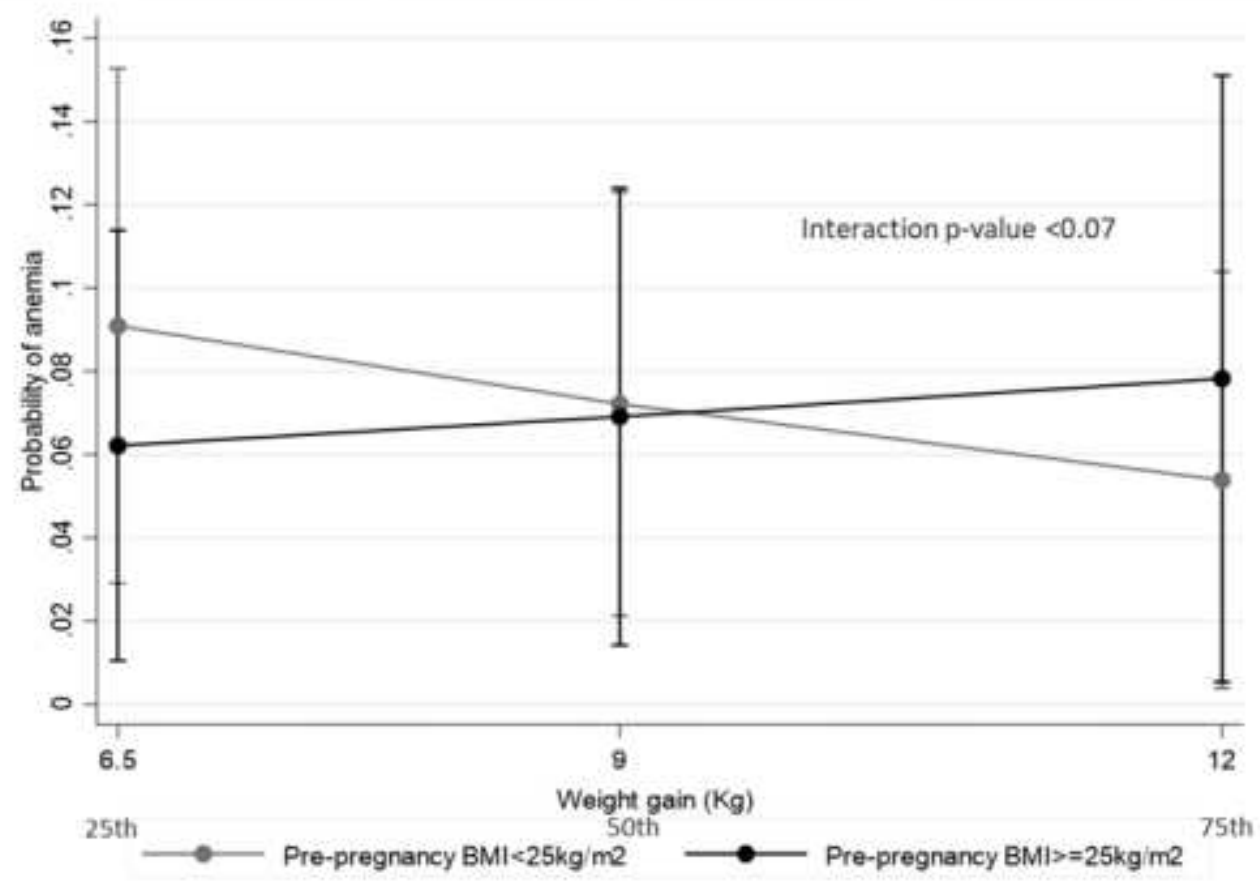

Figure 1

Probability of anemia according to pre-pregnancy BMI status and weight gain (Predicted probabilities and 95\% Confidence Intervals)

\section{Supplementary Files}

This is a list of supplementary files associated with this preprint. Click to download.

- BMC19Dec19tableACP.pdf 